\title{
Safety and efficacy of antibiotics compared with appendicectomy for treatment of uncomplicated acute appendicitis: meta-analysis of randomised controlled trials
}

\author{
(c) $\underset{1}{(1)(8)}$ OPEN ACCESS
}

\author{
Krishna K Varadhan research fellow ${ }^{1}$, Keith R Neal professor ${ }^{12}$, Dileep N Lobo professor ${ }^{1}$ \\ 'Division of Gastrointestinal Surgery, Nottingham Digestive Diseases Centre NIHR Biomedical Research Unit, Nottingham University Hospitals, \\ Queen's Medical Centre, Nottingham NG7 2UH, UK; ${ }^{2}$ Department of Epidemiology and Public Health, Nottingham University Hospitals
}

\begin{abstract}
Objective To compare the safety and efficacy of antibiotic treatment versus appendicectomy for the primary treatment of uncomplicated acute appendicitis.

Design Meta-analysis of randomised controlled trials.

Population Randomised controlled trials of adult patients presenting with uncomplicated acute appendicitis, diagnosed by haematological and radiological investigations.
\end{abstract}

Interventions Antibiotic treatment versus appendicectomy.

Outcome measures The primary outcome measure was complications. The secondary outcome measures were efficacy of treatment, length of stay, and incidence of complicated appendicitis and readmissions.

Results Four randomised controlled trials with a total of 900 patients (470 antibiotic treatment, 430 appendicectomy) met the inclusion criteria. Antibiotic treatment was associated with a $63 \%$ (277/438) success rate at one year. Meta-analysis of complications showed a relative risk reduction of $31 \%$ for antibiotic treatment compared with appendicectomy (risk ratio (Mantel-Haenszel, fixed) 0.69 (95\% confidence interval 0.54 to 0.89$\left.) ; I^{2}=0 \% ; P=0.004\right)$. A secondary analysis, excluding the study with crossover of patients between the two interventions after randomisation, showed a significant relative risk reduction of $39 \%$ for antibiotic therapy (risk ratio 0.61 ( 0.40 to 0.92 ); $I^{2}=0 \% ; P=0.02$ ). Of the $65(20 \%)$ patients who had appendicectomy after readmission, nine had perforated appendicitis and four had gangrenous appendicitis. No significant differences were seen for treatment efficacy, length of stay, or risk of developing complicated appendicitis.

Conclusion Antibiotics are both effective and safe as primary treatment for patients with uncomplicated acute appendicitis. Initial antibiotic treatment merits consideration as a primary treatment option for early uncomplicated appendicitis.

\section{Introduction}

Appendicectomy has been the mainstay for the treatment for acute appendicitis since it was first reported by McBurney in $1889,{ }^{1}$ and the general assumption since the 19 th century has been that in the absence of surgical intervention the disease often progresses from uncomplicated to perforated appendicitis. ${ }^{12}$ The advent of laparoscopic surgery and the low threshold for operative intervention have led to a risk of high negative appendicectomy rates with unnecessary surgery related morbidity. ${ }^{3-5}$ Only $20 \%$ of patients present with complicated appendicitis, and non-operative management with antibiotics and supportive treatment has been explored as a therapeutic option for patients with early uncomplicated appendicitis, with resolution in most of them. ${ }^{6-9}$ Antibiotic treatment was often considered as a bridge to surgery in patients with suspected appendicitis but no clear indications for appendicectomy such as signs of perforation or peritonitis. However, the routine use of antibiotics in patients with uncomplicated acute appendicitis was not well supported, owing to inherent pitfalls in the quality and design of individual studies. ${ }^{10}$ The role of antibiotic treatment in acute uncomplicated appendicitis may have been overlooked mainly on the basis of tradition rather than evidence, considering that other intra-abdominal inflammatory processes such as colonic diverticulitis are primarily managed non-operatively.

This time honoured practice has been challenged recently with reports of less morbidity associated with antibiotic treatment than surgery in uncomplicated acute appendicitis. ${ }^{11-14} \mathrm{With}$ the availability of diagnostic modalities such as computed tomography and ultrasonography, the small group of patients presenting with complicated appendicitis can be identified. Furthermore, epidemiological studies suggest that despite the increasing trend for surgical exploration for suspected 
appendicitis over the years, the incidence of perforated appendicitis has been similar across all age groups. ${ }^{15}{ }^{16}$ However, the management of the large majority with uncomplicated appendicitis warrants further evaluation.

Systematic reviews and meta-analyses of the trials, ${ }^{10} 1718$ including a Cochrane review comparing antibiotic treatment and appendicectomy, ${ }^{19}$ published in recent years summarised the evidence as either in favour of antibiotic treatment or inconclusive. This could possibly result from inclusion of trials with poor methods or retracted since publication, ${ }^{20-22}$ or from simplifying the evidence as a summary of both randomised and non-randomised studies. ${ }^{23}$ The meta-analysis presented here provides a valid and up to date summary of the relevant literature, including a recently published randomised controlled trial of 339 patients with a confirmed diagnosis of uncomplicated appendicitis. ${ }^{24}$ It excludes the study that has been retracted subsequent to publication, ${ }^{21}$ as well as another for which it was not clear if patients were randomised. ${ }^{22}$ The aim of this meta-analysis of randomised controlled trials was to compare antibiotic treatment with appendicectomy for the treatment of uncomplicated acute appendicitis, with particular reference to safety and efficacy.

\section{Methods}

Randomised controlled trials comparing antibiotic treatment with appendicectomy for uncomplicated acute appendicitis in adult patients were eligible for inclusion. We included studies with well defined diagnostic and treatment protocols and which reported at least two of the outcome measures mentioned below. We excluded non-randomised studies, retrospective studies, case series, and studies that reported outcomes in patients with complicated appendicitis (local or contained perforation with an appendicular abscess or mass).

We used method of randomisation, concealment of allocation, blinding, description of dropouts and withdrawals, intention to treat analysis, and duration of follow-up to assess the methodological quality of included randomised controlled trials. Further validation of the methodological quality of individual randomised controlled trials, rating the quality of evidence and strength of recommendations of this meta-analysis, used the grading of recommendations assessment, development, and evaluation (GRADE) system, ${ }^{25}$ as recommended by the Cochrane Collaboration. This included systematic assessments of all randomised controlled trials across five main domains for each outcome: limitations of the study design and execution; inconsistency, indirectness, and imprecision of results; and publication bias. Accordingly, we graded the recommendation for either antibiotic treatment or appendicectomy as very low, low, moderate, or high.

\section{Outcome measures}

We recorded clinical outcomes according to intention to treat analysis where available. The primary outcome measure of this meta-analysis was complications, as reported in the studies (table $1 \Downarrow$ ). However, we included only relevant complications that were reported by all studies such as wound infection and incidence of perforated appendicitis or peritonitis, so that the meta-analysis had a homogeneous group for comparison. We present the results of statistical heterogeneity in the forest plots. The secondary outcome measures were length of primary hospital stay, readmissions, and efficacy of treatment (table $1 \Downarrow$ ). We also report other secondary outcomes such as incidence of perforation, pain, and body temperature where available.

\section{Study selection}

Two authors (KKV and KRN) independently searched the Medline, Embase, and Cochrane Library databases and the Cochrane Controlled Trials Register for randomised controlled trials comparing antibiotic treatment with appendicectomy for acute appendicitis. The search included all studies published between January 1966 and December 2011, regardless of language. Keywords used included antibiotics, surgery, appendicectomy, appendectomy, randomised controlled trial, controlled clinical trial, randomised, placebo, drug therapy, randomly, and trial and were used in combination with the Boolean operators AND, OR, and NOT. We supplemented the search by using the "related article" function. We manually searched bibliographies of randomised controlled trials, meta-analyses, and systematic reviews for studies that were missed in the initial electronic search. Studies that met the inclusion criteria for the meta-analysis were assessed independently, and any disagreements were resolved by discussion with the third author (DNL).

\section{Data collection and statistical analysis}

We retrieved relevant articles identified as eligible for inclusion, and two authors (KKV and KRN) independently collected data for analysis. We did the meta-analysis in accordance with the recommendations of the Cochrane Collaboration, using Review Manager version 5.1 software. We present the summary statistic of dichotomous outcomes as risk ratios for complications and odds ratios for treatment efficacy as appropriate. We used the Mantel-Haenszel method to combine the summary statistic and assessed the statistical heterogeneity by using the $\mathrm{I}^{2}$ method alongside the $\chi^{2} \mathrm{P}$ value. When combining studies of this nature for meta-analysis, we assumed that variation existed between trials in both the design and the methodological quality, so we used a random effect model to provide a conservative estimate of the results. We used a fixed effect model when no heterogeneity existed. We considered the results to be statistically significant at the $\mathrm{P}<0.05$ level if the $95 \%$ confidence interval did not include the value 1 .

For the purpose of this meta-analysis, the antibiotic group comprised patients who were, at the outset, treated with antibiotics at initial presentation when the diagnosis of acute appendicitis was made. On the basis of intention to treat analysis, we also considered patients who failed to recover with antibiotic treatment and subsequently had surgery to be part of the antibiotic group. The appendicectomy group comprised those patients who were randomised to have appendicectomy at initial presentation. We did a separate sensitivity analysis for complications to assess if differences in the antibiotic regimen influenced the treatment outcome.

\section{Results}

\section{Quality assessment and study design}

We considered six trials and included four of them (fig $1 \Downarrow) .^{202426}{ }^{27}$ Of the two not included, one study was retracted after publication, ${ }^{21}$ and one presented no evidence of randomisation. ${ }^{22}$ The box summarises the characteristics of the four included studies. A total of 900 patients with suspected uncomplicated acute appendicitis were randomised to either antibiotic treatment $(\mathrm{n}=470)$ (fig $2 \Downarrow)$ or appendicectomy $(\mathrm{n}=430)$ (fig $3 \Downarrow$ ), on the basis of the treatment protocol of individual studies (see box). Three studies included patients treated in multiple centres, ${ }^{202426}$ and one was a single centre study. ${ }^{27}$ 


\section{Characteristics of included studies}

Vons et $a^{24}$

Methods

Open label, non-inferiority, randomised controlled trial in six academic centres.

Participants

All adults over 18 years with suspected acute appendicitis. Eligible participants had diagnosis of uncomplicated appendicitis by computed tomography, using defined radiological criteria, and were randomised to appendicectomy or antibiotic treatment. Patients who were allergic to antibiotics or iodine, had been on antibiotics before admission, were receiving steroid or anticoagulants, had a history of inflammatory bowel disease, were pregnant, had blood creatinine of $\geq 200 \mu \mathrm{mol} / \mathrm{L}$, or were unable to understand the protocol or consent form were excluded.

Interventions

Patients in both treatment groups were assessed twice a day after admission and were discharged after resolution of pain, fever, and any digestive symptoms. All patients were seen on days $15,30,90,180$, and 360 .

Antibiotics-Intravenous or oral amoxicillin plus clavulanic acid ( $3 \mathrm{~g}$ per day if $<90 \mathrm{~kg}$ or $4 \mathrm{~g}$ for patients $>90 \mathrm{~kg}$ ) for 48 hours. Appendicectomy if no resolution of symptoms after 48 hours. If resolution of symptoms, discharged with antibiotics and reviewed on day 8 . Computed tomography done if persistent pain or fever and possible appendicectomy. If not, antibiotics continued for another 8 days. If persistent symptoms on day 15 , appendicectomy was done.

Surgery-Open or laparoscopic appendicectomy was done according to surgeon's standard practice. Amoxicillin plus clavulanic acid $2 \mathrm{~g}$ at induction of general anaesthesia. Antibiotics were given postoperatively only if complicated appendicitis. Histology was obtained for all specimens.

Outcomes

Primary endpoint-Occurrence of peritonitis within 30 days of initial treatment, diagnosed either at appendicectomy or postoperatively by computed tomography. Secondary endpoints-Number of days with a post-intervention visual analogue scale pain score $\geq 4$, length of stay and absence from work, incidence of complications other than peritonitis within one year, and recurrence of appendicitis after antibiotic treatment (appendicectomy done between 30 days and one year of follow-up, with a confirmed diagnosis of appendicitis).

Hansson et apo

Methods

Randomised controlled trial. Three hospitals included in the study; one hospital used only as a reference cohort for comparison with study and control groups at the other two hospitals. Allocation by date of birth (odd number, antibiotics group; even, surgery group). Questionnaire was sent to all patients after one and 12 months. Telephoned if no response.

Participants

369 patients with positive history, clinical signs, laboratory tests, and, in some cases, ultrasonography, computed tomography, and gynaecological examination. Interventions

Antibiotics - Intravenous cefotaxime $1 \mathrm{~g}$ twice daily and metronidazole for at least 24 hours. Patients when improved were discharged 24 hours later with oral ciprofloxacin $500 \mathrm{mg}$ twice a day and metronidazole $400 \mathrm{mg}$ three times a day for 10 days. If no improvement, intravenous treatment was prolonged.

Surgery-Appendicectomy was done according to author's usual practice, single dose antibiotic prophylaxis, open or laparoscopic technique, and postoperative antibiotic treatment when the appendix was gangrenous or perforated.

All specimens were sent for histological examination.

Outcomes

Treatment efficacy, complications, recurrences and reoperations, length of antibiotic treatment, abdominal pain after discharge from hospital, length of hospital stay, and sick leave. The total costs for the primary hospital stay were analysed for each patient.

\section{Styrud et afe}

Methods

Patients were asked to participate if appendicectomy was planned, and those who agreed were subsequently randomised to either surgery or antibiotic treatment. Patients were monitored at the end of one week, six weeks, and one year.

Participants

Male patients, 18-50 years of age, admitted to six different hospitals between 1996 and 1999. No women were enrolled by decision of the local ethics committee. Patients with suspected appendicitis with a $\mathrm{C}$ reactive protein concentration $>10 \mathrm{mg} / \mathrm{L}$ and with no clinical signs of perforation.

Interventions

Antibiotics-Intravenous cefotaxime $2 \mathrm{~g} 12$ hourly and tinidazole $800 \mathrm{mg}$ daily for two days. Discharged after two days with oral ofloxacin $200 \mathrm{mg}$ twice daily and tinidazole $500 \mathrm{mg}$ twice daily for 10 days. If symptoms not improved within first 24 hours, appendicectomy was done. All conservatively treated patients with a suspected recurrence of appendicitis had surgery.

Patients randomised to surgery had open or laparoscopic operations at the surgeon's discretion. All removed appendixes were sent for histology.

Outcomes

Hospital stay, sick leave, diagnosis at operation, recurrences, and complications.

Eriksson et $a^{27}$

Methods

Randomisation of patients admitted with history and clinical signs of acute appendicitis. Ultrasonography and laboratory tests: white blood cell count and C reactive protein to identify patients with a high probability for acute appendicitis.

Participants

Patients with typical history and clinical signs, positive findings at ultrasound, and either increased white blood cell count and $\mathrm{C}$ reactive protein values or high $\mathrm{C}$ reactive protein or white blood cell count on two occasions within a four hour interval. Initial randomisation of 20 patients in each group, but one patient from the antibiotic group developed increased abdominal pain and generalised peritonitis and had surgery, and subsequent data were discounted.

Interventions

Conservative-Cefotaxime $2 \mathrm{~g} 12$ hourly and tinidazole $800 \mathrm{mg}$ for two days. Discharged after two days with oral ofloxacin $200 \mathrm{mg}$ twice daily and tinidazole $500 \mathrm{mg}$ twice daily for eight days. Patients were excluded from the study in the event of increased abdominal pain and generalised peritonitis and had surgery. Surgery-Treated with antibiotics for 24 hours only in the event of bowel perforation or in cases of abdominal spillage. Discharged when conditions were satisfactory and when patients wished to return home. Histology obtained for all specimens.

Follow-up-All patients were seen at 6,10 , and 30 days after admission and blood tested for white blood cell count and $C$ reactive protein; pain scores and temperature recorded. Abdominal and rectal examination on days 6 and 10 . Stools examined for Clostridium difficile toxin at day 30 . Ultrasonography on days 10 and 30 .

Outcomes

Pain scores (every six hours using a visual analogue scale), morphine consumption, white blood cell count and temperature, positive diagnosis at surgery, hospital stay, wound infection, and recurrent appendicitis. 
The diagnosis of acute appendicitis was made from the history and clinical signs and complemented with laboratory tests for raised inflammatory markers. Diagnosis of acute appendicitis at admission was confirmed by ultrasonography in one study ${ }^{27}$ and by computed tomography in two studies, ${ }^{20}{ }^{24}$ although this was done only in some patients in the study by Hansson et al. ${ }^{20}$ Vons et al used computed tomography to exclude patients from the study if they had complicated appendicitis according to the criteria of presence of extra-luminal gas, peri-appendiceal fluid, or disseminated intra-peritoneal fluid. ${ }^{24}$

Randomisation methods were reported as computer generated, ${ }^{24}$ external randomisation, ${ }^{26}$ and by date of birth. ${ }^{20}$ The

randomisation method was not clear in one study. ${ }^{27}$ Concealment of allocation was documented in two studies as use of sealed envelopes $^{24}{ }^{26}$; it was not reported in the other two studies. ${ }^{20} 27$ Vons et al described their study as an open label, non-inferiority trial. ${ }^{24} \mathrm{O}$ wing to the nature of interventions used, none of the studies was blinded. All studies documented a median follow-up of one year. Hansson et al reported protocol violation after randomisation and crossover of patients between groups in their study and presented the results as both intention to treat and evaluated per protocol. ${ }^{20}$ Three studies described dropouts and withdrawals. ${ }^{20} 2427$

\section{Analysis of outcomes}

Table $2 \Downarrow$ summarises outcomes for individual randomised controlled trials. A large number of patients crossed over from the antibiotic group to the appendicectomy group (96/202) after allocation to antibiotic treatment and appendicectomy in the study by Hansson et al. ${ }^{20}$ Therefore, we did a secondary analysis excluding data from this study to avoid the risk of any selection bias and over-estimation of treatment effects (figures $4 \Downarrow, 5 \Downarrow$, and $6 \Downarrow$ ). Quality assessment of the included studies according to the GRADE approach showed some limitations of the study design and inconsistency, ${ }^{20}$ but no obvious indirectness or imprecision of reporting of results (tables $3 \Downarrow$ and $4 \Downarrow$ ). Based on the above assessments, the quality of evidence presented for each outcome ranged from "low" to "moderate." Owing to the inclusion of only four studies, a funnel plot analysis (data not shown) showed the presence of risk of publication bias for reporting of complications, which downgraded the quality rating. Given that the search resulted in only four eligible studies, asymmetry cannot be reliably judged. However, no correspondence related to the papers identified any unpublished negative studies.

\section{Complications}

Meta-analysis of complications (fig $4 \Downarrow$ ) showed a relative risk reduction of $31 \%$ in the antibiotic treatment group compared with the appendicectomy group (risk ratio (Mantel-Haenszel, fixed) 0.69 (95\% confidence interval 0.54 to 0.89 ); $\mathrm{I}^{2}=0 \%$, $\mathrm{P}=0.004)$. A secondary analysis excluding the data from the study with crossover of patients between the groups showed a significant reduction in the risk of complications by $39 \%$ (relative risk reduction), in the antibiotic treatment group compared with the appendicectomy group (risk ratio $0.61(0.40$ to 0.92 ); $\mathrm{I}^{2}=0 \%, \mathrm{P}=0.02$ ) (fig $4 \Downarrow$ ). Comparison of studies using only cefuroxime plus metronidazole or tinidazole with amoxicillin plus clavulanic acid showed no significant differences between the two groups.

\section{Length of stay}

All studies reported length of primary hospital stay. Except for the study by Hansson et $\mathrm{al},{ }^{20}$ which reported a reduced length of stay in the antibiotic treated group, no significant differences were noted in the other studies despite a reduced trend being seen in the antibiotic group. The forest plot of comparison for length of stay (fig $5 \Downarrow$ ) also showed no significant difference between the antibiotic treatment group and the appendicectomy group (mean difference (inverse variance, random) 0.34 (-0.19 to 0.87$) ; \mathrm{I}^{2}=48 \%, \mathrm{P}=0.20$ ).

\section{Treatment efficacy}

A simple comparison of efficacy of treatment between two entirely different treatments such as surgery and antibiotics for which treatment failure is a possibility would not be truly appropriate. The actual treatment protocol in the antibiotic arms of all four trials was antibiotics with surgery if required versus immediate surgery, and with this definition both trial arms achieve $100 \%$ in resolution of acute appendicitis and also disease at one year. However, we have compared broader aspects of the two treatment options by including the effect of these treatments on outcomes such as recurrences and complications as a marker of treatment efficacy. Thus, the summary of outcomes table (table $2 \Downarrow$ ) shows the results for secondary outcomes for antibiotic treatment and appendicectomy. The data entered for individual studies represent the number of patients who were treated successfully with antibiotics, which ranged between $44 \%$ and $85 \%$. In the appendicectomy group, the numbers represent patients who were treated successfully with appendicectomy and also had a positive diagnosis of appendicitis on histology.

\section{Complicated appendicitis}

The forest plot of comparison for risk of complicated appendicitis (fig $6 \Downarrow$ ) showed no difference between antibiotic treatment and appendicectomy (risk ratio 0.58 (0.18 to 1.90 ); $\mathrm{I}^{2}=74 \%, \mathrm{P}=0.37$ ).

Vons et al studied the incidence of complicated appendicitis, with peritonitis at surgery and peritonitis within 30 days of treatment (diagnosed either by appendicectomy or postoperatively by computed tomography) as a primary endpoint. ${ }^{24}$ Twenty-three (19\%) of the 119 patients in the appendicectomy group had peritonitis, of whom $21 \mathrm{had}$ peritonitis identified at surgery and two had post-therapeutic peritonitis within 30 days. Fourteen of the 120 patients in the antibiotic group had appendicectomy within 30 days, of whom $9(8 \%)$ had peritonitis identified at surgery and two $(2 \%)$ had postoperative peritonitis within 30 days. Only three patients had complicated appendicitis during subsequent follow-up in the antibiotic treated group. Interestingly, the computed tomography findings of intraluminal stercoliths were comparable in the two treatment groups. Twenty-two (18\%) of 119 patients in the appendicectomy group had stercoliths, of whom nine had complicated appendicitis. In the antibiotic group, 19 (16\%) of 120 patients had stercoliths, of whom six had no improvement of appendicitis with antibiotic treatment. No significant differences were reported between the two groups for duration of pain, hospital stay, or disability.

Hansson et al reported that $43 / 202$ patients randomised to antibiotic treatment had either local or general peritonitis compared with 47/167 patients randomised to appendicectomy. ${ }^{20}$ Ninety-six patients randomised to antibiotic therapy had appendicectomy subsequently, of whom 25 had peritonitis. On the basis of per protocol analysis, 50/250 patients had perforation in the surgery group compared with $6 / 119$ patients in the antibiotic group. This included $3 / 12$ recurrences after antibiotic treatment. Forty-two patients in the appendicectomy group were 
reported to have gangrenous appendicitis, 128 had phlegmonous appendicitis, and 30 were reported to have other diagnoses. However, this group included 83 patients who crossed over from antibiotic treatment to appendicectomy evaluated per protocol.

In the study by Styrud et $\mathrm{al},{ }^{26}$ six of 120 patients who underwent surgery had perforation, whereas seven of the 15 patients (total 128 patients) in the antibiotic group who had surgery during their primary admission had perforation. Of those who had recurrences, $5 / 16$ patients had perforation in the antibiotic group. Eriksson et al reported one perforation each in the surgery and antibiotic groups. ${ }^{27}$

A total of 13 patients who were readmitted after successful initial antibiotic treatment had either perforated or gangrenous appendicitis compared with 22 patients (10 perforated and 12 gangrenous appendicitis) in those who crossed over to surgery after initial randomisation to the antibiotic group $(n=126)$. The overall risk of perforated or gangrenous appendicitis in the antibiotic treated group was $7.4 \%$

\section{Readmissions}

Figure $2 \Downarrow$ shows that $68 / 345$ (20\%) patients treated with antibiotics were readmitted with recurrence of symptoms. In this group, four patients had normal appendix and 13 (19\%) had complicated appendicitis. Three patients were treated successfully with another course of antibiotics.

\section{Pain and temperature}

Vons et al did not report any significant differences in pain score between appendicectomy and antibiotic treatment (mean 2.70 $(\mathrm{SD} 1.07) v 1.63$ (1.35); $\mathrm{P}=0.13) .{ }^{24} \mathrm{~A}$ per protocol analysis showed that a significantly higher proportion of patients had some kind of abdominal pain during their first post-treatment year in the antibiotic group compared with those having surgery in the study by Hansson et al (mean 5 (SD 1) $v 8$ (1); $\mathrm{P}<0.05) .{ }^{20}$ Styrud et al did not report pain and temperature. ${ }^{26}$ Eriksson et al also reported a significant decrease in the duration of pain on days 6 and 10, morphine consumption, and temperature in patients managed with antibiotics, compared with those who had appendicectomy $(\mathrm{P}<0.01)$, during hospital admission. ${ }^{27}$

\section{Discussion}

This meta-analysis of four randomised controlled trials including 900 patients comparing the efficacy of antibiotic treatment with that of appendicectomy in patients with uncomplicated appendicitis has shown that antibiotics are a safe initial treatment, with a significant reduction in the risk of complications compared with appendicectomy. We found no significant differences in either length of stay or incidence of complicated appendicitis. Antibiotic treatment was associated with a $63 \%$ success rate and a reduced risk of complications. About $20 \%$ of patients who were treated with antibiotics had appendicectomy for recurrence of symptoms, and of these only about one in five had complicated appendicitis.

\section{Strengths of study}

Our meta-analysis compared two different treatment modalities, each with its own specific complications such as postoperative adhesions in the appendicectomy group and recurrence in the antibiotic group. Additionally, considering antibiotic failure requiring appendicectomy to be a complication when all patients in the other group had the same operation highlights the problems encountered when comparing two very different interventions. Furthermore, not all studies reported administration of prophylactic antibiotic, which may have influenced outcomes in the appendicectomy group. In this context, we believe that by reporting length of stay as a marker in assessing the frequency and severity of complications of treatment when comparing two different treatment modalities further adds to the evidence.

Except for the risk of complications, the meta-analysis of the other outcomes showed a high risk of statistical heterogeneity. However, the GRADE analysis of the quality of included studies across all domains showed that the strength of evidence for complications and length of hospital stay was "moderate," whereas the strength of evidence for risk of complicated appendicitis was "low" (table $3 \Downarrow$ ) owing to the presence of bias and inconsistency of reporting across outcomes. Specifically, this result concurred with the statistically significant reduction in the risk of complications despite the downgrading of the quality of evidence due to selective reporting of this outcome in most of the studies. Thus, this meta-analysis suggests that evidence exists to support the safe use of antibiotics initially in the treatment of uncomplicated appendicitis. Excluding the data from the study with crossover of patients only strengthened the evidence and showed a significant reduction in the risk of complications with an absence of statistical heterogeneity. However, the results did not differ significantly for other outcomes.

\section{Limitations of study}

The major confounders that may have had an influence on the outcomes are diagnosis of appendicitis, type and duration of antibiotic treatment, reporting of complications, and planned discharge after either antibiotic treatment or appendicectomy. All studies included patients with history and clinical signs of acute appendicitis with positive laboratory tests, but routine radiological confirmation of the diagnosis was used for inclusion in only some studies. ${ }^{24}{ }^{27}$ Although only some patients had scans in one study, ${ }^{20}$ no scans were done in the study by Styrud et al, ${ }^{26}$ in which $97 \%$ of patients treated with antibiotics were presumed to have appendicitis, on the basis of high $\mathrm{C}$ reactive protein concentrations with associated positive clinical signs. Moreover, only patients aged between 18 and 50 years were included and women were excluded from this study, ${ }^{26}$ potentially contributing to selection bias.

Antibiotics were administered intravenously in the first 24-48 hours, followed by oral administration for a further 8-10 days, but they were continued beyond the initial course of treatment in some patients with no clinical improvement. However, Vons et al administered antibiotics intravenously only to patients who had nausea or vomiting and orally to all others. ${ }^{24}$ Furthermore, patients randomised to the appendicectomy group were likely to be discharged earlier, if no complicated appendicitis was noted at surgery, than were those randomised to the antibiotics group. Hansson et al reported complications as both major and minor complications,${ }^{20}$ whereas others reported mainly wound infections, recurrences, and incidence of perforated appendicitis. ${ }^{24} 26$ Similarly, patients who were noted to have complicated appendicitis received antibiotics postoperatively, which may have also influenced the outcomes in the surgery group. Vons et al used amoxicillin with clavulanic acid, ${ }^{24}$ whereas the other studies used cefotaxime with either metronidazole or tinidazole. ${ }^{20}{ }^{26}$ Follow-up with computed tomography to detect post-therapeutic peritonitis was not done routinely in all patients in the surgery group, and they were assessed a week later than the antibiotic group. ${ }^{24}$ 
A perforation rate of $15-25 \%$ after acute appendicitis has been reported in the literature. ${ }^{28-30}$ However, in this meta-analysis, the incidence of perforation was $8 \%$ in the antibiotic group, and about $63 \%$ of patients were successfully treated with antibiotics. We found no increased risk of developing complicated appendicitis if patients did not have an early appendicectomy, suggesting that antibiotic treatment is as safe an option as appendicectomy in the primary treatment of uncomplicated appendicitis. However, $30-40 \%$ of patients who were noted to have stercoliths had complicated appendicitis. Hence, primary antibiotic treatment in this group of patients should be used with caution.

About one in five patients is likely to be readmitted after initial successful treatment with antibiotics, and of those who are readmitted one in five may have complicated appendicitis (fig $2 \Downarrow$ ). One study reported no differences in the length of stay after readmission between patients who had perforations and those who had inflamed appendixes. ${ }^{26}$ Evidence shows that prolonged delay of surgical treatment does not necessarily increase the risk of perforation in patients with pathological evidence of resolving appendicitis. ${ }^{31}$ Also, one study excluded female patients, thus slightly reducing the generalisability of the results. Given that one of the differential diagnoses in women is salpingitis, a condition treated with antibiotics, and the rate of complicated appendicitis was not increased with initial antibiotic treatment, this is unlikely to be of particular importance.

\section{Comparison with other studies}

A Cochrane review by Wilms et al included randomised and quasi-randomised studies to study the effectiveness of antibiotic treatment compared with appendicectomy. ${ }^{19}$ The outcome measures were recovery within two weeks and major complications including recurrence, and the authors considered a $20 \%$ margin of non-inferiority to be clinically relevant. However, on the basis of this analysis, they reported that the studies were of low to moderate quality and the results were inconclusive. For reasons mentioned earlier, including recurrences as a complication that is unique to only one group does not allow a fair comparison for the risk of complications. Secondly, minor complications such as clostridium or fungal infection and urinary tract infection were included, when not all studies reported these outcomes as a complication.

Furthermore, negative appendicectomy was considered as a minor complication, when the number of patients in the antibiotic group without appendicitis cannot be truly ascertained without an appendicectomy. This review also included a study that has since been retracted, ${ }^{21}$ as well as one in which it was not clear if patients were randomised. ${ }^{22}$ Another review reported the treatment efficacy of appendicectomy to be significantly higher than that of antibiotics and defined this outcome for the antibiotic group as the number of patients treated successfully with antibiotics with no recurrences and for the appendicectomy group as the number of patients with positive histology of appendicitis. ${ }^{18}$ However, the risk of complications was reduced in the antibiotic group and no differences were noted in length of stay or perforated appendicitis.

Similarly, the review by Liu et al included the above mentioned studies and also a retrospective study by the authors, ${ }^{12}$ but concluded that antibiotic treatment results in $31 \%$ fewer complications compared with appendicectomy. ${ }^{17}$ They reported that "antibiotic failure," defined as lack of improvement or clinical progression within 24-48 hours after the treatment was started, when the patient had appendicectomy, was between $5 \%$ and $11.8 \%$ and the incidence of recurrent appendicitis was $14.2 \%$. The results of the aforementioned studies, which used different statistical designs and outcomes of interest, each with its own definitions, are largely inconclusive despite some evidence in favour of antibiotic treatment. Early appendicectomy has been the norm when the diagnosis of appendicitis is suspected or confirmed at admission, in the belief that this may prevent complications such as perforation or peritonitis. This dogma stems from the pathophysiological hypothesis that appendicitis is a progressive disease, from an uncomplicated stage to one with complications of gangrene, perforation, or peritonitis, and that any delay in treatment increases the risk of complications. ${ }^{2}$ The risk of infertility in women with complicated appendicitis has been reported to be $3.2-4.8 \% .^{32} 33$ However, whether women in the childbearing age group will be put at increased risk of infertility because of treatment of appendicitis with antibiotics is not known. Given that the rate of complicated appendicitis in each group was similar, any reduction in infertility from initial antibiotics will be minimal.

The availability of diagnostic modalities such as computed tomography, with $100 \%$ sensitivity and $95 \%$ specificity, ${ }^{34} 35$ combined with the low morbidity associated with laparoscopy, ${ }^{36}{ }^{37}$ has increased the diagnostic accuracy for appendicitis and reduced the threshold for surgery for appendicitis that may have resolved spontaneously. Furthermore, to increase the complexity of the diagnosis of appendicitis, a histologically normal variant known as "neuroimmune appendicitis", characterised by abnormal concentrations of neuropeptides, neuronal sprouting, and possibly combined with the immunological response, has been attributed to the relief of pain in patients who had a histologically normal appendix removed. $^{38-40}$

Antibiotic treatment may delay an appendicectomy in patients who are not improving, but this delay does not disadvantage the patient with an increased risk of complications. The overall risk of complications is lower, as appendicectomy is avoided in two thirds of patients.

Recent evidence points towards a change in epidemiological trends and the distinct pattern of perforated and non-perforated appendicitis over the years, suggesting that they may be two different entities. ${ }^{15} 4142$ Although the incidence of negative (or "unnecessary") appendicectomy and non-perforated appendicitis has been increasing with time, the incidence of perforated appendicitis has not changed substantially. ${ }^{1528}$ This is also reflected by the fact that about $63 \%$ of patients in the antibiotic arms of the studies included in this meta-analysis avoided an appendicectomy. Whether mere mucosal or sub-mucosal inflammation, as will be reported commonly in the histology of removed appendixes for uncomplicated appendicitis, is of any clinical significance is debatable. ${ }^{40} 43$ The view that early antibiotic treatment for uncomplicated appendicitis is safe is supported by the finding by Vons et al that none of the patients who had successful treatment with antibiotics had post-treatment peritonitis. ${ }^{24}$ However, this incidence differed between patients who failed to improve with antibiotic treatment (14\%, two of 14 patients) and those who had appendicectomy (1.7\%, two of 120 patients).

Our meta-analysis thus makes it clear that antibiotic treatment is associated with a reduced risk of complications and no increased risk of perforation in patients having a delayed appendicectomy after antibiotic failure. Given the increase in non-perforated appendicitis diagnosed with more frequent use of computed tomography and laparoscopy, a careful "wait, watch, and treat" policy may be adopted in those patients considered to have uncomplicated appendicitis or in whom the diagnosis is uncertain, as in these patients correct diagnosis rather than an early appendicectomy is the key. For patients 
with clear signs of perforation or peritonitis, after an initial period of active observation, early appendicectomy still remains the "gold standard."

\section{Health policy implications}

Appendicectomy is one of the most common operations performed, and small increases in health benefit in the management of acute appendicitis deliver considerable health gains. Antibiotic treatment as the initial management of uncomplicated appendicitis is safe and effective. Starting antibiotics when the diagnosis of uncomplicated acute appendicitis is made, with reassessment of the patient, will prevent the need for the most appendectomies, reducing patient morbidity. Oral antibiotics can be continued after discharge, allowing potentially shorter lengths of stay.

\section{Conclusions}

This meta-analysis of four randomised controlled trials comparing antibiotic treatment and appendicectomy for uncomplicated acute appendicitis showed that antibiotics can be used safely as primary treatment in patients presenting with acute uncomplicated appendicitis. Antibiotic treatment was not associated with an increased perforation rate compared with surgery, nor were any significant differences seen in the length of stay or treatment efficacy between antibiotics and appendicectomy. An early trial of antibiotics merits consideration as the initial treatment option for uncomplicated appendicitis. The possibility that perforated and non-perforated appendicitis could have different patterns and pathological processes needs further evaluation. Perhaps, uncomplicated acute appendicitis should be treated akin to other conditions such as acute colonic diverticulitis in which antibiotic treatment plays an important role.

This paper was presented at the annual scientific meeting of the Society of Academic and Research Surgery in Nottingham, UK, in January 2012. An abstract will be published in the British Journal of Surgery.

Contributors: All three authors contributed to the conception and design of the study, to analysis and interpretation of data, to drafting the article and revising it critically for important intellectual content, and to final approval of the version to be published. DNL is the guarantor.

Funding: KKV was funded by a research fellowship from the Nottingham Digestive Diseases Centre NIHR Biomedical Research Unit. The funders had no role in the design, execution, and writing up of the study.

Competing interests: All authors have completed the Unified Competing Interest form at http://www.icmje.org/coi_disclosure.pdf (available on request from the corresponding author) and declare: no support from any organisation for the submitted work; no financial relationships with any organisations that might have an interest in the submitted work in the previous three years, no other relationships or activities that could appear to have influenced the submitted work.

Ethical approval: Not needed.

Data sharing: No additional data available.

1 McBurney C. Experiences with early operative interference in cases of disease of the vermiform appendix. NY Med $J$ 1889;50:1676-84.

2 Fitz RH. Perforating inflammation of the vermiform appendix. Am J Med Sci 1886;92:246-321.

3 Coursey CA, Nelson RC, Patel MB. Do more preoperative CT scans mean fewer negative appendectomies? A 10 year study. Radiology 2010;254:460-8

4 Konstantinidis KM, Anastasakou KA, Vorias MN, Sambalis GH, Georgiou MK, Xiarchos AG. A decade of laparoscopic appendectomy: presentation of 1026 patients with suspected appendicitis treated in a single surgical department. J Laparoendosc Adv Surg Tech A 2008:18:248-58

5 Ming PC, Yan TY, Tat LH. Risk factors of postoperative infections in adults with complicated appendicitis. Surg Laparosc Endosc Percutan Tech 2009;19:244-8.

6 Coldrey E. Five years of conservative treatment of acute appendicitis. J Int Coll Surg 1959;32:255-61.
7 Campbell MR, Johnston SL, Marshburn T. Nonoperative treatment of suspected appendicitis in remote medical care environments. J Am Coll Surg 2004:198:822-30.

8 Aivazian VP. State of intramural neural apparatus of the vermiform process in "cecum mobile" syndrome. Zh Eksp Klin Med 1975;15:70-6.

9 Gurin NN. The efficacy of the conservative treatment of patients with acute appendicitis on board ships at sea. Vestn Khir 1992:148:144-50.

10 Varadhan KK, Humes DJ, Neal KR, Lobo DN. Antibiotic therapy versus appendectomy for acute appendicitis: a meta-analysis. World J Surg 2009;34:199-209.

11 Blomqvist PG, Andersson RE, Granath F, Lambe MP, Ekbom AR. Mortality after appendectomy in Sweden, 1987-1996. Ann Surg 2001;233:455-60.

12 Liu K, Ahanchi S, Pisaneschi M, Lin I, Walter R. Can acute appendicitis be treated by antibiotics alone? Am Surg 2007;73:1161-5.

13 Simillis C, Symeonides P, Shorthouse AJ, Tekkis PP. A meta-analysis comparing conservative treatment versus acute appendectomy for complicated appendicitis (abscess or phlegmon). Surgery 2010;147:818-29.

14 Park HC, Kim BS, Lee BH. Efficacy of short-term antibiotic therapy for consecutive patients with mild appendicitis. Am Surg 2011;77:752-5.

15 Livingston EH, Woodward WA, Sarosi GA, Haley RW. Disconnect between incidence of nonperforated and perforated appendicitis: implications for pathophysiology and management. Ann Surg 2007:245:886-92.

16 Luckmann R. Incidence and case fatality rates for acute appendicitis in California: a population-based study of the effects of age. Am J Epidemiol 1989;129:905-18.

17 Liu K, Fogg L. Use of antibiotics alone for treatment of uncomplicated acute appendicitis: a systematic review and meta-analysis. Surgery 2011;150:673-83.

18 Ansaloni L, Catena F, Coccolini F, Ercolani G, Gazzotti F, Pasqualini E, et al. Surgery versus conservative antibiotic treatment in acute appendicitis: a systematic review and meta-analysis of randomized controlled trials. Dig Surg 2011:28:210-21.

19 Wilms IM, de Hoog DE, de Visser DC, Janzing HM. Appendectomy versus antibiotic treatment for acute appendicitis. Cochrane Database Syst Rev 2011;11:CD008359.

20 Hansson J, Korner U, Khorram-Manesh A, Solberg A, Lundholm K. Randomized clinical trial of antibiotic therapy versus appendicectomy as primary treatment of acute appendicitis in unselected patients. Br J Surg 2009;96:473-81.

21 Malik AA, Bari S-u. Conservative management of acute appendicitis [retraction in: J Gastrointest Surg 2011;15:2302]. J Gastrointest Surg 2009;13:966-70.

22 Turhan AN, Kapan S, Kutukcu E, Yigitbas H, Hatipoglu S, Aygun E. Comparison of operative and non operative management of acute appendicitis. Ulus Travma Acil Cerrah Derg 2009;15:459-62.

23 Fitzmaurice GJ, McWilliams B, Hurreiz H, Epanomeritakis E. Antibiotics versus appendectomy in the management of acute appendicitis: a review of the current evidence. Can J Surg 2011;54:6610.

24 Vons C, Barry C, Maitre S, Pautrat K, Leconte M, Costaglioli B, et al. Amoxicillin plus clavulanic acid versus appendicectomy for treatment of acute uncomplicated appendicitis: an open-label, non-inferiority, randomised controlled trial. Lancet 2011;377:1573-9.

25 Brozek J, Oxman A, Schünemann H. GRADEpro [computer program]. Version 3.2 for Windows. 2008. http://ims cochrane.org/revman/gradepro.

26 Styrud J, Eriksson S, Nilsson I, Ahlberg G, Haapaniemi S, Neovius G, et al. Appendectomy versus antibiotic treatment in acute appendicitis. a prospective multicenter randomized controlled trial. World J Surg 2006;30:1033-7.

27 Eriksson S, Granstrom L. Randomized controlled trial of appendicectomy versus antibiotic therapy for acute appendicitis. Br J Surg 1995;82:166-9.

28 Guller U, Rosella L, McCall J, Brugger LE, Candinas D. Negative appendicectomy and perforation rates in patients undergoing laparoscopic surgery for suspected appendicitis. Br J Surg 98:589-95.

29 Andersson RE, Hugander A, Thulin AJ. Diagnostic accuracy and perforation rate in appendicitis: association with age and sex of the patient and with appendicectomy rate. Eur J Surg 1992;158:37-41.

30 Styrud J, Eriksson S, Segelman J, Granstrom L. Diagnostic accuracy in 2,351 patients undergoing appendicectomy for suspected acute appendicitis: a retrospective study 1986-1993. Dig Surg 1999;16:39-44.

31 Bowers WF, Hughes CW, Bonilla KB. The treatment of acute appendicitis under suboptimal conditions. U S Armed Forces Med J 1958;9:1545-57.

32 Lopez PP, Cohn SM, Popkin CA, Jackowski J, Michalek JE. The use of a computed tomography scan to rule out appendicitis in women of childbearing age is as accurate as clinical examination: a prospective randomized trial. Am Surg 2007;73:1232-6.

33 Mueller BA, Daling JR, Moore DE, Weiss NS, Spadoni LR, Stadel BV, et al. Appendectomy and the risk of tubal infertility. N Engl $J$ Med 1986;315:1506-8.

34 Rao PM, Rhea JT, Novelline RA, McCabe CJ, Lawrason JN, Berger DL, et al. Helical CT technique for the diagnosis of appendicitis: prospective evaluation of a focused appendix CT examination. Radiology 1997;202:139-44.

35 Rhea JT, Rao PM, Novelline RA. Helical CT and three-dimensional CT of facial and orbital injury. Radiol Clin North Am 1999;37:489-513.

36 McGreevy JM, Finlayson SR, Alvarado R, Laycock WS, Birkmeyer CM, Birkmeyer JD. Laparoscopy may be lowering the threshold to operate on patients with suspected appendicitis. Surg Endosc 2002;16:1046-9.

37 Sauerland S, Lefering R, Neugebauer EA. Laparoscopic versus open surgery for suspected appendicitis. Cochrane Database Syst Rev 2004:4:CD001546.

38 Di Sebastiano P, Fink T, di Mola FF, Weihe E, Innocenti P, Friess $\mathrm{H}$, et al. Neuroimmune appendicitis. Lancet 1999;354:461-6.

39 Stead RH, Franks AJ, Goldsmith CH, Bienenstock J, Dixon MF. Mast cells, nerves and fibrosis in the appendix: a morphological assessment. J Pathol 1990;161:209-19.

40 Wang $\mathrm{Y}$, Reen DJ, Puri P. Is a histologically normal appendix following emergency appendicectomy always normal? Lancet 1996;347:1076-9.

41 Rivera-Chavez FA, Peters-Hybki DL, Barber RC, Lindberg GM, Jialal I, Munford RS, et al. Innate immunity genes influence the severity of acute appendicitis. Ann Surg 2004;240:269-77.

42 Rivera-Chavez FA, Wheeler H, Lindberg G, Munford RS, O'Keefe GE. Regional and systemic cytokine responses to acute inflammation of the vermiform appendix. Ann Surg 2003:237:408-16.

43 Puylaert JB, Rutgers PH, Lalisang RI, de Vries BC, van der Werf SD, Dorr JP, et al. A prospective study of ultrasonography in the diagnosis of appendicitis. N Engl J Med 1987;317:666-9.

Accepted: 23 February 2012 


\section{What is already known on this topic}

Acute appendicitis has traditionally been believed to often progress from an uncomplicated state to perforated appendicitis in the absence of surgical intervention

Recent observational studies and randomised controlled trials support the role of antibiotics as primary treatment for uncomplicated acute appendicitis

However, the results are limited by methodological quality and study design, contributing to heterogeneity in results

\section{What this study adds}

This meta-analysis, using robust methodology, has shown a significant reduction in risk of complications with antibiotic treatment compared with appendicectomy

No significant differences were noted between antibiotic treatment and appendicectomy for length of stay, efficacy of treatment, or risk of complicated appendicitis

Antibiotics merit consideration as primary treatment in patients presenting with uncomplicated acute appendicitis

\section{Cite this as: BMJ 2012;344:e2156}

This is an open-access article distributed under the terms of the Creative Commons Attribution Non-commercial License, which permits use, distribution, and reproduction in any medium, provided the original work is properly cited, the use is non commercial and is otherwise in compliance with the license. See: $\mathrm{http}: / /$ creativecommons.org/licenses/by$\mathrm{nc} / 2.0 /$ and http://creativecommons.org/licenses/by-nc/2.0/legalcode. 


\section{Tables}

\section{Table 1| Definitions of outcome measures}

\begin{tabular}{|c|c|c|}
\hline Outcome measure & Antibiotic treatment & Appendicectomy \\
\hline Complications & $\begin{array}{l}\text { Perforated/gangrenous appendicitis or peritonitis and wound infection } \\
\text { (in patients who failed antibiotic treatment and had appendicectomy } \\
\text { subsequently) }\end{array}$ & Perforated appendicitis or peritonitis and wound infection \\
\hline $\begin{array}{l}\text { Length of primary hospital } \\
\text { stay }\end{array}$ & $\begin{array}{l}\text { Number of days of inpatient admission for patients who were treated with } \\
\text { antibiotics following admission and discharged with oral antibiotics }\end{array}$ & $\begin{array}{l}\text { Number of days of inpatient admission for patients who had } \\
\text { appendicectomy and were discharged with further follow-up }\end{array}$ \\
\hline Readmissions & $\begin{array}{l}\text { Patients who were readmitted for operations or antibiotic related } \\
\text { problems, such as diarrhoea, and including wound infections after surgery } \\
\text { for failed antibiotic treatment; also those who were readmitted for } \\
\text { recurrent symptoms }\end{array}$ & $\begin{array}{l}\text { Patients who were readmitted with postoperative } \\
\text { complications such as intra-abdominal collections, adhesive } \\
\text { obstruction, or wound infections }\end{array}$ \\
\hline Treatment efficacy & $\begin{array}{l}\text { Patients who were successfully treated with antibiotics only and had } \\
\text { none of the following: failure of antibiotic treatment or recurrence of } \\
\text { symptoms needing appendicectomy; development of any post-therapeutic } \\
\text { or postoperative complications }\end{array}$ & $\begin{array}{l}\text { Patients who were successfully treated with appendicectomy } \\
\text { and had none of the following: no appendicitis on histology; } \\
\text { development of any post-therapeutic or postoperative } \\
\text { complications including readmissions }\end{array}$ \\
\hline
\end{tabular}




\begin{tabular}{|c|c|c|c|c|c|c|c|c|c|c|c|c|c|c|}
\hline \multirow[b]{2}{*}{ Study } & \multicolumn{2}{|c|}{$\begin{array}{c}\text { No of } \\
\text { patients }\end{array}$} & \multicolumn{2}{|c|}{ Age (years) } & \multicolumn{2}{|c|}{$\begin{array}{c}\text { Successful } \\
\text { treatment } \\
\text { with } \\
\text { intervention }\end{array}$} & \multicolumn{2}{|c|}{ Complications } & \multicolumn{2}{|c|}{ Recurrences } & \multicolumn{2}{|c|}{$\begin{array}{c}\text { Mean (SD) } \\
\text { length of } \\
\text { stay (days) }\end{array}$} & \multicolumn{2}{|c|}{$\begin{array}{l}\text { Diagnoses in patients who had } \\
\text { appendicectomy }\end{array}$} \\
\hline & A & $\mathbf{S}$ & A & $\mathbf{S}$ & A & $\mathbf{S}$ & A & $\mathbf{S}$ & A & $\mathbf{S}$ & A & $\mathbf{S}$ & Antibiotics & Surgery \\
\hline $\begin{array}{l}\text { Vons } \\
2011^{24}\end{array}$ & 120 & 119 & $\begin{array}{l}\text { Mean } 34 \\
(\mathrm{SD} 12)\end{array}$ & $\begin{array}{l}\text { Mean } 38 \\
(\mathrm{SD} 13)\end{array}$ & 81 & 119 & 3 & 12 & 30 & 0 & $\begin{array}{c}3.96 \\
(4.87)\end{array}$ & $\begin{array}{l}3.04 \\
(1.5)\end{array}$ & $\begin{array}{l}44 \text { had } \\
\text { appendicectomy: } 14 \\
\text { within } 30 \text { days ( } 9 \\
\text { complicated, } 4 \\
\text { uncomplicated, } 1 \\
\text { normal); } 30 \text { between } 30 \\
\text { days and } 1 \text { year ( } 3 \\
\text { complicated, } 23 \\
\text { uncomplicated, } 4 \\
\text { normal) }\end{array}$ & $\begin{array}{l}\text { Appendicectomy: } \\
119 \text { (21 complicated } \\
\text { appendicitis, } 98 \\
\text { uncomplicated } \\
\text { appendicitis) }\end{array}$ \\
\hline $\begin{array}{l}\text { Hansson } \\
2009^{20}\end{array}$ & 202 & 167 & $\begin{array}{l}\text { Mean } 38 \\
(\text { SEM 1) }\end{array}$ & $\begin{array}{l}\text { Mean } 38 \\
(\text { SEM 1) }\end{array}$ & 83 & 142 & 51 & 55 & 15 & 0 & $\begin{array}{c}3 \\
(0.1)\end{array}$ & $\begin{array}{c}3 \\
(0.2)\end{array}$ & $\begin{array}{l}119 \text { patients had } \\
\text { antibiotics and } 83 \\
\text { others crossed over to } \\
\text { surgery; } \\
\text { appendicectomy: } 21 \\
\text { (out of } 119 \text { ); } 9 \\
\text { appendicitis in primary } \\
\text { admission: } 3 \\
\text { phlegmonous; } 3 \\
\text { gangrenous, } 3 \\
\text { perforated. ( } 1 \text { normal } \\
\text { appendix, } 1 \text { surgically } \\
\text { treatable); } 12 / 15 \\
\text { recurrences had } \\
\text { appendicectomy: } 8 \\
\text { phlegmonous, } 1 \\
\text { gangrenous, } 3 \\
\text { perforated (3 treated } \\
\text { with antibiotics) }\end{array}$ & $\begin{array}{l}83 \text { crossed over to } \\
\text { surgery from } \\
\text { antibiotics } \\
\text { (evaluated per } \\
\text { protocol); } \\
\text { appendicectomy: } \\
250 ; 220 \text { (128 } \\
\text { phlegmonous, } 42 \\
\text { gangrenous, } 50 \\
\text { perforated); other } \\
\text { diagnoses: } 30 \text { ( } 3 \\
\text { other surgically } \\
\text { treatable causes, } 14 \\
\text { surgically } \\
\text { non-treatable, and } \\
13 \text { normal) }\end{array}$ \\
\hline $\begin{array}{l}\text { Styrud } \\
2006^{26}\end{array}$ & 128 & 124 & $\begin{array}{l}\text { Range } \\
18-50 ; \\
\text { mean } \\
\text { not } \\
\text { reported }\end{array}$ & $\begin{array}{l}\text { Range: } \\
\text { 18-50; } \\
\text { mean } \\
\text { not } \\
\text { reported }\end{array}$ & 97 & 120 & 4 & 17 & 16 & 0 & $\begin{array}{l}3.0 \\
(1.4)\end{array}$ & $\begin{array}{c}2.6 \\
(1.2)\end{array}$ & $\begin{array}{l}\text { Appendicectomy:31 (15 } \\
\text { primary, } 16 \\
\text { readmissions); } 1 \\
\text { primary had terminal } \\
\text { ileitis; } 12 \text { perforated; } 18 \\
\text { phlegmonous }\end{array}$ & $\begin{array}{l}\text { Appendicitis: } 120 \text { (6 } \\
\text { perforated, } 1 \\
\text { gangrenous, } 3 \\
\text { mesenteric adenitis, } \\
1 \text { no pathology) }\end{array}$ \\
\hline $\begin{array}{l}\text { Eriksson } \\
1995^{27}\end{array}$ & 20 & 20 & $\begin{array}{c}\text { Mean } 27 \\
\text { (range } \\
18-53 \text { ) }\end{array}$ & $\begin{array}{c}\text { Mean } 35 \\
\text { (range } \\
19-75)\end{array}$ & 13 & 17 & 0 & 2 & 7 & 0 & $\begin{array}{l}3.1 \\
(0.3)\end{array}$ & $\begin{array}{c}3.4 \\
(1.9)\end{array}$ & $\begin{array}{l}\text { Appendicectomy: } 8 \text { (1 } \\
\text { primary, } 7 \\
\text { readmissions); } 6 \\
\text { phlegmonous and } 1 \\
\text { perforated }\end{array}$ & $\begin{array}{l}\text { Appendicitis } 17 \text { (8 } \\
\text { phlegmonous, } 8 \\
\text { gangrenous, } 1 \\
\text { perforated); } 3 \\
\text { normal }\end{array}$ \\
\hline Total & 470 & 430 & & & 274 & 398 & 58 & 86 & 68 & 0 & & & $98 / 104$ & $357 / 394$ \\
\hline
\end{tabular}

$A=$ antibiotics; $S=$ surgery. 


\begin{tabular}{|c|c|c|c|c|c|c|}
\hline Critical outcome & $\begin{array}{l}\text { Participants } \\
\text { (studies); follow-up Risk of bias* }\end{array}$ & Inconsistency* & Indirectness & Imprecision & Publication bias & $\begin{array}{l}\text { Overall quality of } \\
\text { evidence } \dagger\end{array}$ \\
\hline \multicolumn{7}{|l|}{ Complications: } \\
\hline All studies & 900 (4 studies); 1 year Serious ${ }^{a, b, c}$ & Serious $s^{\mathrm{a}, \mathrm{d}}$ & No & No & Undetected & $\begin{array}{l}+/+/-/-; \text { low due to risk of } \\
\text { bias and inconsistency }\end{array}$ \\
\hline $\begin{array}{l}\text { Studies with no } \\
\text { crossover of patients }\end{array}$ & 531 (3 studies); 1 year Serious ${ }^{d}$ & $\begin{array}{l}\text { No serious } \\
\text { inconsistency }\end{array}$ & No & No & Undetected & $\begin{array}{l}+/+/+/-; \text { moderate due to } \\
\text { risk of bias }\end{array}$ \\
\hline \multicolumn{7}{|l|}{$\begin{array}{l}\text { Length of primary } \\
\text { hospital stay: }\end{array}$} \\
\hline All studies & 900 (4 studies); 1 year Serious ${ }^{\mathrm{a}, \mathrm{b}, \mathrm{c}}$ & Serious $^{a}$ & No & No & Undetected & $\begin{array}{l}+/+/-/-; \text { low due to risk of } \\
\text { bias and inconsistency }\end{array}$ \\
\hline $\begin{array}{l}\text { Studies with no } \\
\text { crossover of patients }\end{array}$ & 531 (3 studies); 1 year Serious ${ }^{d}$ & $\begin{array}{l}\text { No serious } \\
\text { inconsistency }\end{array}$ & No & No & Undetected & $\begin{array}{l}+/+/+/-; \text { moderate due to } \\
\text { risk of bias }\end{array}$ \\
\hline \multicolumn{7}{|l|}{$\begin{array}{l}\text { Risk of complicated } \\
\text { appendicitis: }\end{array}$} \\
\hline All studies & 896 (4 studies); 1 year Serious ${ }^{a, b, d}$ & Serious $^{a}$ & No & No & Undetected & $\begin{array}{l}+/+/-/-; \text { low due to risk of } \\
\text { bias and inconsistency }\end{array}$ \\
\hline $\begin{array}{l}\text { Studies with no } \\
\text { crossover of patients }\end{array}$ & 527 (3 studies); 1 year Serious ${ }^{d}$ & Serious $^{\mathrm{e}}$ & No & No & Undetected & $\begin{array}{l}+/+/-/-; \text { low due to risk of } \\
\text { bias and inconsistency }\end{array}$ \\
\hline \multicolumn{7}{|c|}{$\begin{array}{l}\text { *Basis for assumed risk: a) incomplete accounting of patients and events; b) randomisation by date of birth; c) crossover of patients after randomisation; d) excluded } \\
\text { female patients; e) definitions of outcome vary between trials. } \\
\text { †GRADE Working Group grades of evidence: high quality-further research very unlikely to change confidence in estimate of effect; moderate quality-further } \\
\text { research likely to have important impact on confidence in estimate of effect and may change estimate; low quality-further research very likely to have important } \\
\text { impact on confidence in estimate of effect and likely to change estimate; very low quality—very uncertain about estimate. }\end{array}$} \\
\hline
\end{tabular}




\begin{tabular}{|c|c|c|c|c|c|}
\hline \multirow[b]{2}{*}{ Critical outcome } & \multicolumn{2}{|c|}{ Study event rates (\%) } & \multirow{2}{*}{$\begin{array}{l}\text { Relative effect (95\% } \\
\text { Cl) }\end{array}$} & \multicolumn{2}{|r|}{ Anticipated absolute effects } \\
\hline & With control & With antibiotics & & Risk with control & Risk difference with antibiotics ${ }^{*}(95 \% \mathrm{Cl})$ \\
\hline \multicolumn{6}{|l|}{ Complications: } \\
\hline \multirow[t]{4}{*}{ All studies } & \multirow[t]{4}{*}{$108 / 430(25)$} & \multirow[t]{4}{*}{$84 / 470(18)$} & \multirow[t]{4}{*}{$0.69(0.54$ to 0.89$)$} & \multicolumn{2}{|r|}{ Study population } \\
\hline & & & & 251 per 1000 & 78 (28 to 116$)$ fewer per 1000 \\
\hline & & & & \multicolumn{2}{|r|}{ Moderate† } \\
\hline & & & & 194 per 1000 & 60 (21 to 89$)$ per 1000 \\
\hline \multirow[t]{4}{*}{ Studies with no crossover of patients } & \multirow[t]{4}{*}{$50 / 263(19)$} & \multirow[t]{4}{*}{$31 / 268(12)$} & \multirow[t]{4}{*}{0.61 (0.4 to 0.92$)$} & \multicolumn{2}{|r|}{ Study population } \\
\hline & & & & 190 per 1000 & 74 (15 to 114 ) fewer per 1000 \\
\hline & & & & \multicolumn{2}{|r|}{ Moderate† } \\
\hline & & & & 186 per 1000 & 73 (15 to 112$)$ fewer per 1000 \\
\hline \multicolumn{6}{|l|}{ Length of primary hospital stay: } \\
\hline All studies & 430 & 470 & & & 0.2 higher ( 0.16 lower to 0.56 higher) \\
\hline Studies with no crossover of patients & 263 & 268 & & & 0.34 higher ( 0.19 lower to 0.87 higher) \\
\hline \multicolumn{6}{|l|}{ Risk of complicated appendicitis: } \\
\hline \multirow[t]{4}{*}{ All studies } & \multirow[t]{4}{*}{$129 / 509(25)$} & \multirow[t]{4}{*}{$54 / 387(14)$} & \multirow[t]{4}{*}{$0.68(0.38$ to 1.21$)$} & \multicolumn{2}{|r|}{ Study population } \\
\hline & & & & 253 per 1000 & 81 fewer ( 157 fewer to 53 more) per 1000 \\
\hline & & & & \multicolumn{2}{|r|}{ Moderate $\dagger$} \\
\hline & & & & 272 per 1000 & 87 fewer (169 fewer to 57 more) per 1000 \\
\hline \multirow[t]{4}{*}{ Studies with no crossover of patients } & \multirow[t]{4}{*}{$37 / 259(14)$} & \multirow[t]{4}{*}{$25 / 268(9)$} & \multirow[t]{4}{*}{$0.61(0.2$ to 1.89$)$} & \multicolumn{2}{|r|}{ Study population } \\
\hline & & & & 143 per 1000 & 56 fewer ( 114 fewer to 127 more) per 1000 \\
\hline & & & & \multicolumn{2}{|r|}{ Moderate $\dagger$} \\
\hline & & & & 177 per 1000 & 69 fewer ( 142 fewer to 158 more) per 1000 \\
\hline
\end{tabular}




\section{Figures}

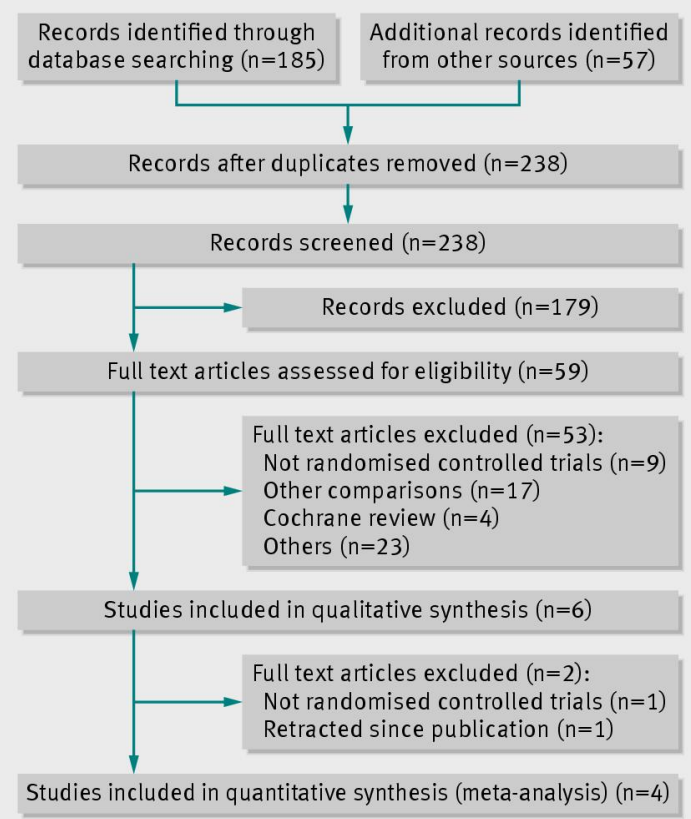

Fig 1 PRISMA flow diagram

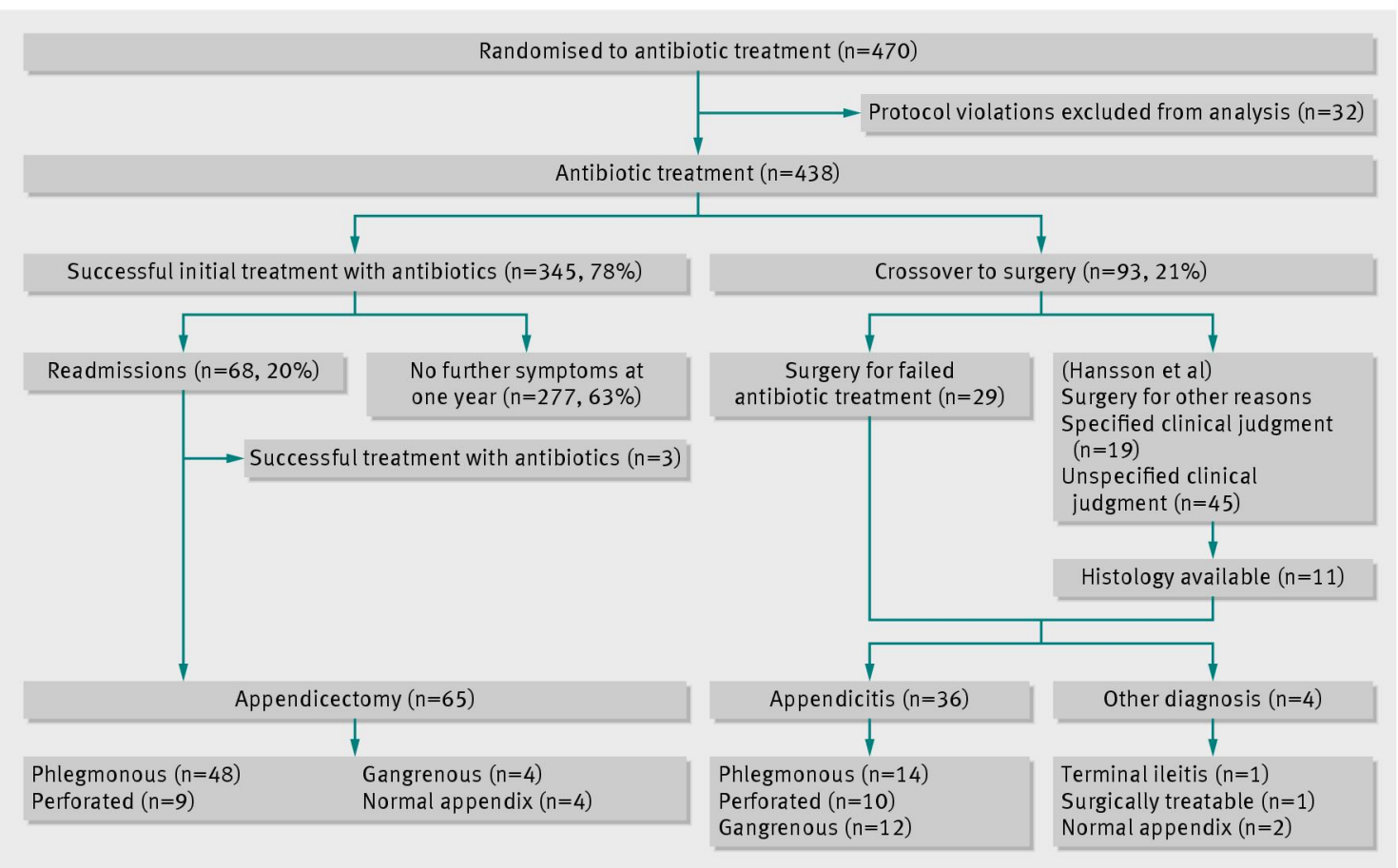

Fig 2 Treatment outcome: antibiotics 


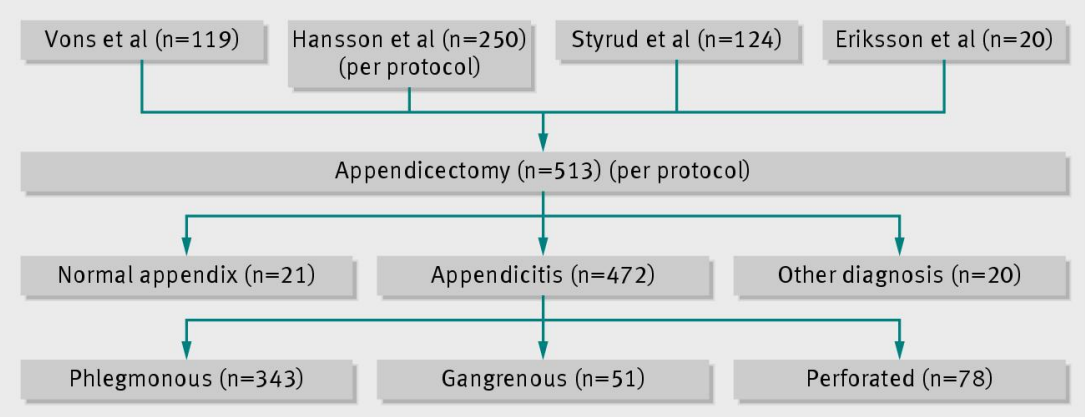

Fig 3 Treatment outcome: appendicectomy

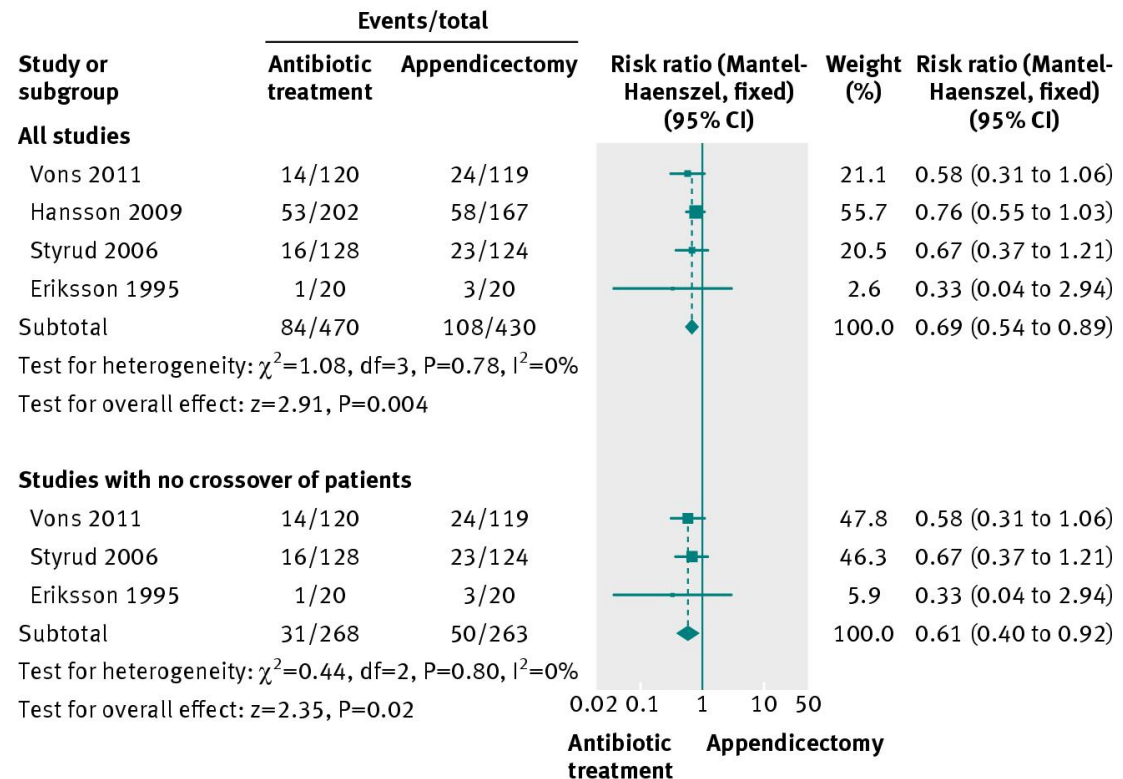

Fig 4 Antibiotic treatment versus appendicectomy for uncomplicated appendicitis: forest plot for complications

\begin{tabular}{|c|c|c|c|c|c|}
\hline \multirow[b]{2}{*}{$\begin{array}{l}\text { Study or } \\
\text { subgroup } \\
\text { All studies }\end{array}$} & \multicolumn{2}{|c|}{ Mean (SD)/total } & \multirow[b]{2}{*}{$\begin{array}{l}\text { Mean difference } \\
\text { (inverse variance, } \\
\text { random) }(95 \% \mathrm{Cl})\end{array}$} & \multirow[b]{2}{*}{$\begin{array}{c}\text { Weight } \\
(\%)\end{array}$} & \multirow[b]{2}{*}{$\begin{array}{l}\text { Mean difference } \\
\text { (inverse variance, } \\
\text { random) }(95 \% \mathrm{Cl})\end{array}$} \\
\hline & $\begin{array}{l}\text { Antibiotic } \\
\text { treatment }\end{array}$ & Appendicectomy & & & \\
\hline Vons 2011 & $3.96(4.87) / 120$ & $3.04(1.5) / 119$ & & 11.5 & $0.92(0.01$ to 1.83$)$ \\
\hline Hansson 2009 & $3(0.1) / 202$ & $3(0.3) / 167$ & i & 43.3 & $0.00(-0.05$ to 0.05$)$ \\
\hline Styrud 2006 & $3(1.4) / 128$ & $2.6(1.2) / 124$ & & 32.4 & $0.40(0.08$ to 0.72$)$ \\
\hline Eriksson 1995 & $3.1(0.3) / 20$ & $3.4(1.9) / 20$ & & 12.9 & $-0.30(-0.16$ to 0.56$)$ \\
\hline Subtotal & 470 & 430 & & 100.0 & $0.20(-0.16$ to 0.56$)$ \\
\hline \multicolumn{6}{|c|}{$\begin{array}{l}\text { Test for heterogeneity: } \tau^{2}=0.08, \chi^{2}=10.16, d f=3 \text {, } \\
P=0.02, I^{2}=70 \%\end{array}$} \\
\hline \multicolumn{6}{|c|}{ Test for overall effect: $z=1.07, P=0.29$} \\
\hline \multicolumn{6}{|c|}{ Studies with no crossover of patients } \\
\hline Vons 2011 & $3.96(4.87) / 120$ & $3.04(1.5) / 119$ & & 22.3 & $0.92(0.01$ to 1.83$)$ \\
\hline Styrud 2006 & $3(1.4) / 128$ & $2.6(1.2) / 124$ & & 53.1 & $0.40(0.08$ to 0.72$)$ \\
\hline Eriksson 1995 & $3.1(0.3) / 20$ & $3.4(1.9) / 20$ & & 24.7 & $-0.30(-0.19$ to 0.87$)$ \\
\hline Subtotal & 268 & 263 & & 100.0 & $0.34(-0.19$ to 0.87$)$ \\
\hline \multicolumn{6}{|c|}{ Test for heterogeneity: $\tau^{2}=0.11, \chi^{2}=3.86, d f=2$, } \\
\hline \multicolumn{3}{|c|}{$P=0.15, I^{2}=48 \%$} & -1 & 2 & \\
\hline \multicolumn{3}{|c|}{ Test for overall effect: $z=1.27, P=0.20$} & $\begin{array}{l}\text { Antibiotic Appen } \\
\text { treatment }\end{array}$ & cectomy & \\
\hline
\end{tabular}

Fig 5 Antibiotic therapy versus appendicectomy for uncomplicated appendicitis: forest plot for length of primary hospital stay 


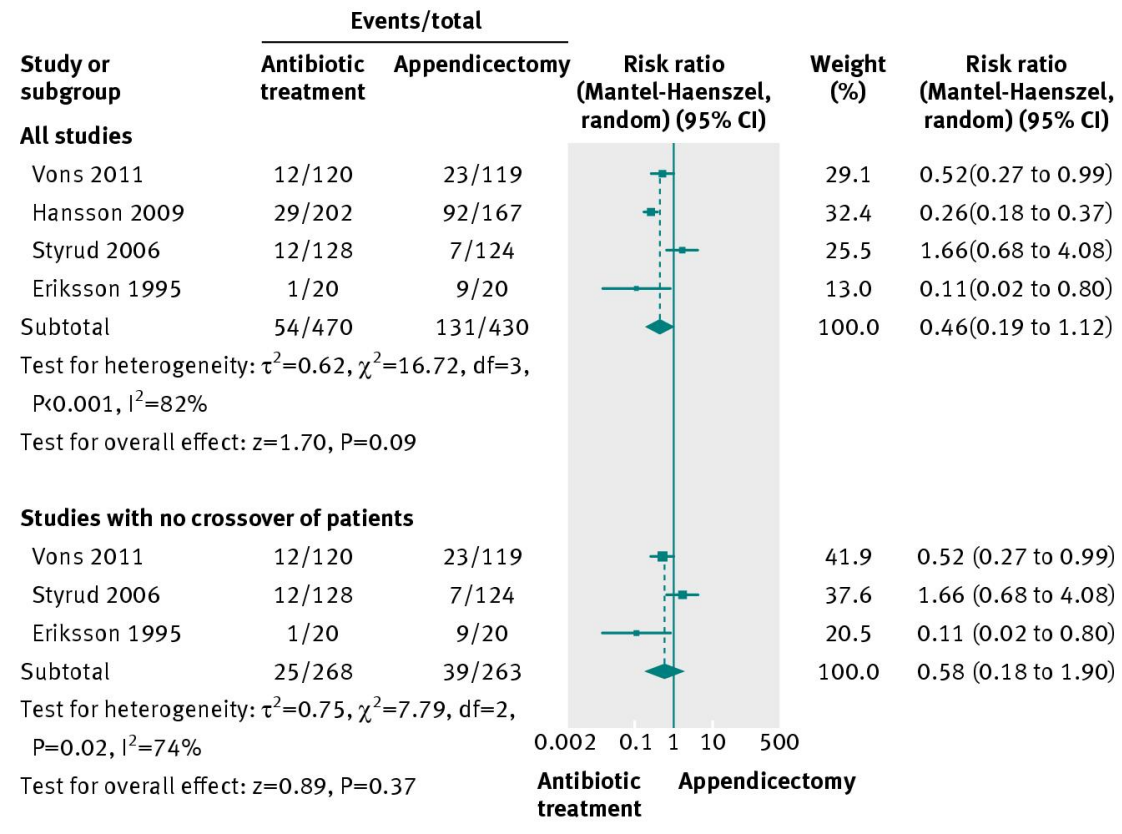

Fig 6 Antibiotic therapy versus appendicectomy for uncomplicated appendicitis: forest plot for risk of complicated appendicitis 